\title{
A inclusão social da pessoa com deficiência no mercado de trabalho
}

\author{
*Maria Celeste de Sousa Lopes, **Maria João Rodrigues \\ * IESF/ Universidade Portucalense, **Ministério da Educação
}

\begin{abstract}
Resumo
A inclusão educativa e a inclusão social tem sido uma preocupação constante de todos os que se interessam pelos direitos humanos e por uma sociedade mais justa e democrática. A busca pelos mesmos direitos sociais, quer sejam educativos, quer no que se refere ao emprego, está na base desta preocupação. Já no final do século XX começaram a surgir os primeiros estudos sobre a inclusão de pessoas portadores de Deficiência no mercado de trabalho. Neste contexto a presente comunicação escrita tem como finalidade dar a conhecer os resultados de uma pequena investigação que teve como objectivos identificar os fatores que levaram ao sucesso de pessoas com deficiências no mercado de trabalho segundo o ponto de vista dos empregadores.
\end{abstract}

Palavras chave: deficiência, trabalho, sucesso

\section{Introdução}

No final dos anos XX começaram a surgir os primeiros estudos sobre a integração da pessoa com deficiência no Mercado de trabalho. Daí até aos nossos dias esta é uma questão cada vez mais preocupante em que a sociedade em geral começa a compreender que depende dela própria a capacidade de aceitação e integração destas pessoas.

A busca pelos mesmos direitos Sociais, no que se refere ao emprego ao deslocar-se livremente na sociedade, ao direito aos mesmos bens e serviços públicos está na base desta preocupação. Tanto as empresas públicas como as privadas são desafiadas a implementar programas que assegurem o acolhimento à diversidade humana nos locais de trabalho (Silva, Alves, Ribas, \& dos Santos, 2010). A adoção de cotas de inserção na função pública veio concretizar esta preocupação, levando a que empresas privadas de grande porte também adotassem estratégias, e levou também à sensibilização de alguns empresários de pequenas e médias empresas.

De acordo com Von Groote et al. (2011), “A deficiência faz parte da condição humana. É correto pensar que praticamente todos, em algum momento da vida, sofrerão algum tipo de incapacidade, temporária ou permanente”(p. 269) Ao que ainda acrescenta, “A deficiência é complexa, e as intervenções necessárias para superar as desvantagens causadas por ela são múltiplas, sistémicas e irão variar conforme o contexto" (p. 269).

Segundo Monteiro (2009) é importante promover oportunidades de emprego para pessoas com deficiência no mercado regular de trabalho. E não é assim tão difícil
- nem para o empregador, nem para o empregado. Contratar pessoas com deficiências introduz alguma inovação, diversidade e até qualidade no trabalho. É positivo para a imagem da empresa e é-o, ainda mais, para o colaborador contratado, porque promove a sua inserção social. O simples facto de ter um emprego dá-lhe motivação, capacidades e independência para desempenhar da melhor forma as suas tarefas.

Segundo a Organização Mundial da Saúde citado em Von Groote et al., (2011), no seu Relatório mundial sobre a deficiência, "Quase todos os trabalhos podem ser realizados produtivamente por uma pessoa com deficiência, e com o ambiente certo a maioria dessas pessoas pode ser produtiva” (p. 259).

Para Carvalho-Freitas \& Marques, (2009), a perceção das Pessoas com Deficiencia acerca das dificuldades que enfrentam para se inserirem no mercado de trabalho, o sentimento da perda de oportunidade de trabalho por possuírem deficiência e a discriminação sentida ao disputarem uma vaga de emprego podem contribuir para a supervalorização da oportunidade do emprego formal e, como consequência, para a tendência a avaliarem positivamente a sua situação laboral. Verifica-se que o trabalho representa uma forma de obterem ganhos económicos, mas, acima de tudo, caracteriza-se como uma fonte de satisfação pessoal. O trabalho possibilita-lhes uma forma de socialização e integração com outras pessoas, o aumento de sua autoestima e a oportunidade de se afirmarem como indivíduos capazes.

Por outro lado, segundo Silva et al. (2010), a presença de pessoas com deficiência pode trazer beneficios às empresas visto que compartilhar o ambiente de trabalho com estas pessoas pode ser um estimulo aos demais trabalhadores, no sentido de criarem relações mais afetivas e um ambiente de trabalho mais humanizado. Hoje, mais do que nunca, as empresas que conseguem realizar esta prática desfrutam de uma maior agregação de valor à sua imagem.

Não podemos ignorar em toda esta problemática, a importância da família e da escola ao longo da vida da pessoa portadora de deficiência, pois é em função das suas expectativas que se poderão encontrar alternativas para problemas que, em determinada altura, podem ser sentidos como insolúveis. A escola desempenha, igualmente, um papel crucial nomeadamente no acompanhamento (nos anos terminais de inserção na educação escolar) promovendo estratégias de diferenciação curricular que atendam aos aspetos necessários a um bom desenvolvimento pessoal e social dos jovens não somente na sua relação com o trabalho, mas em todos os momentos da sua vida de modo a que eles possam assumir-se verdadeiramente como pessoas (Afonso, 2005). 
Segundo Bota (2013), a transição para a vida pós escolar é de extrema importância, e constitui um desafio para a escola. Da eficácia da sua operacionalização depende o futuro de muitos jovens; sem o seu contributo teríamos uma sociedade mais empobrecida, mais incompleta, uma vez que das suas diferenças nasce a diversidade e o pluralismo. É da confluência e aceitação dessas singularidades que se imprime um maior humanismo à nossa existência, por isso a aceitação da diferença inicia-se no seio das próprias famílias, nas escolas, mas tem necessariamente de extravasar o espaço escolar e prolongar-se pela vida, em contextos sociais adequados e diversos, na comunidade e no trabalho, envolvendo todos os cidadãos, colhendo-se assim os frutos de um processo que começou a germinar essencialmente ao longo da transição para a vida pós escolar do aluno.

\section{Metodo}

A Metodologia utilizada no presente trabalho foi exploratória com abordagem qualitativa. A técnica de recolha de dados utilizada foi a entrevista.

\section{Participantes}

Foram selecionadas 8 empresas que empregam pessoas com deficiência nos quadros, 7 (micro, pequenas e médias empresas) localizadas no Norte do País e uma grande empresa de nível nacional.

\section{Procedimentos}

Em primeiro lugar realizaram-se contactos no sentido de conhecer e selecionar a amostra de empresas para o presente estudo. Depois foi elaborado um documento a solicitar a autorização das entrevistas nas empresas selecionadas

Seguidamente calendarizaram-se e realizaram-se as entrevistas. O guião das mesmas teve em conta o enquadramento teórico com vista a corroborar, ou não, o mesmo, e os indicadores em estudo Os empresários foram previamente informados do objetivo e enquadramento do estudo, do qual iriam fazer parte, e da forma como este lhes seria aplicado. Foi assegurada a total confidencialidade das empresas participantes.

Após a transcrição das respostas, fez-se uma análise qualitativa das mesmas. e que vão ser apresentados de acordo com os seguintes indicadores:1) Formação; 2) Tipos de apoio; 3) Estagios; 4) Modicações; 5) Aceitação; 6) Aspectos facilitadores; 7) Barreiras.

As empresas por questões logísticas foram codificadas com as letras do alfabeto de $\mathrm{A} \mathrm{a} \mathrm{H}$.

\section{Resultados}

\section{Formação}

Todas as empresas realçaram a importância da formação. A maioria refere que é uma formação diferente e constante. Uma outra acrescenta que a formação é dada em "posto de trabalho" e duas outras acrescentam que a formação é exatamente igual a de qualquer outro funcionario.

Uma das empresas (A) considera que é uma formação diferente e muito mais direcionada. "A formação tem de ser realizada devagarinho, segundo um método repetitivo e durar mais tempo". Já a Empresa $€$ acrescenta que os funcionários precisam sempre de formação pois quando chegam não conhecem o serviço. A maior diferença na formação "é o ter de lidar com o funcionário com deficiência com muita atenção pois ele coloca muitas questões durante o dia, o que requer muita paciência. A formação é muito repetitiva e requerem mais tempo de aprendizagem.”

\section{Apoios}

Todas as empresas entrevistadas consideram os apoios importantes, contudo, quatro delas, referem nunca terem beneficiado de qualquer tipo de apoio.Três acrescentam, ainda, que a ajuda é pontual ao nivel de descontos para a segurança social e uma delas acrescenta ainda ajuda nos transportes e no seguro.

\section{Estágios}

Três das empresas (A, B e E) referiram que não dão qualquer estágio. Três das empresas ( $\mathrm{C}, \mathrm{G}$ e H) não dá neste momento mas já deram e estão abertas a novas experiências neste âmbito, A empresa (F) já deu vários estágios e tem neste momento um jovem a realizar estagio. Considera que estes estágios ajudam no sentido de dar mais tempo aos deficientes a integrarem-se pois aprendem mais calmamente. A empresa (D) tem cerca de 13 jovens em experiência de trabalho.

\section{Modificações}

Relativamente às modificações arquitetónicas, técnicas ou organizacionais para admitir pessoas com deficiência, nenhuma das empresas precisou fazer modificações para os funcionários que tem atualmente. Referenciaram que "São todos autónomos e adaptaram-se bem”.

\section{Aceitação}

Quanto ao esforço em promover a aceitação e o companheirismo entre as pessoas com deficiências e os restantes colegas de trabalho, na empresa (A) tal não foi necessário pois são já eles próprios um centro de emprego protegido.

Nas empresas (B) e (€) foi necessário sensibilizar um pouco no sentido de respeitar a pessoa com deficiência como um trabalhador igual a qualquer outro.

Na empresa (D). Existiu um grande acompanhamento inicial por parte dos recursos humanos e informalmente foi feita uma boa sensibilização aos restantes trabalhadores. $\mathrm{Na}$ empresa (F) houve uma integração plena com tutores. Nas empresas (C) e (H) nada foi necessário.

\section{Aspectos faciltadores}

Quanto aos aspetos decisivos que levam ao sucesso na 
integração profissional de pessoas com deficiência foram:

- A motivação do funcionario foi apontada por quatro empresas (A, B, D e F).

- A qualificação foi considerada importante nos casos das empresas (A, B, D e H).

- Salário justo foi apontado pelas empresas (A, B, C, G e H). A empresa (B) assume pagar um salário menor em relação aos restantes trabalhadores dado que o funcionário trabalha a tempo reduzido, A empresa (C) diz que o funcionário ganha o mesmo que os outros mas que de certa forma é injusto pois não produz o mesmo.

- As boas condições de trabalho foi um aspeto apontado pelas empresas (A, B, C, E e H).

- $\quad$ O apoio da família foi considerado de extrema importância por parte das empresas (A, B, D, G e $\mathrm{H}$ ) . A empresa (D) considera mesmo que o apoio familiar faz toda a diferença e que isso se verifica, internamente, nos casos que lá têm.

- O bom ambiente de trabalho foi um aspeto salientado pelas empresas (A, B, D, E, G e H).

- Uma boa seleção do posto de trabalho, no sentido de ver as competências e onde a pessoa melhor se enquadra foi um aspeto salientado pelas empresas (A, B, C, D, E e H).

- A oportunidade de crescimento profissional foi um aspeto salientado pela empresa (G),

- $\quad$ Sentimento de utilidade e noção da importância da função que desempenha foi um aspeto salientado pelas empresas (A, B, E e H).

- A não descriminação e serem tratados com respeito e dignidade pelas empresas (F e H).

\section{Barreiras}

Numa análise às principais barreiras que impedem a inserção profissional das pessoas com deficiência, as mais apontadas estão relacionadas com a: 1) Falta de paciencia Um das empresas (A) considera "que é preciso ter muita paciencia, tempo para estar com eles e explicar a mesma coisa várias vezes, e mesmo disponibilizar uma pessoa para verificar o trabalho deles”; 2) perigosidade das máquinas; 3) a falta de incentivos estatais, 4) a falta de preparação escolar ao nivel da confiança, autonomía e sociabilidade; 5) a discriminação social.

\section{Análise e discussão dos resultados}

Tendo como amostra empresas onde predomina o emprego a funcionários com limitações intelectuais, podemos verificar alguma uniformidade de resultados nestes casos, paralelamente aos outros tipos de deficiência, Esta uniformidade verifica-se no caso, por exemplo, da formação onde é perentória a necessidade de uma formação diferente, mais direcionada e que tem de ser realizada devagarinho, segundo um método repetitivo. É necessário explicar bem e repetir sempre que necessário como se deve fazer cada trabalho. De acordo com algumas empresas o funcionário deve ser sempre acompanhado.

Quanto ao tipo de apoios que recebem por parte do estado por empregarem pessoas com deficiência, apenas a empresa A (centro de emprego protegido) recebe do IEFP, através do calculo do défice de rentabilidade, a comparticipação com a parte não rentável. De salientar que à excepção de um pequeno desconto na Segurança Social ou mesmo uma ou outra situação de estágio inicial, mais nenhuma empresa tem qualquer tipo de benefícios o que nos leva a concluir que, ou as empresas estão mal informadas sobre as ajudas estatais possíveis ou estas ficam de facto aquém do desejado.

As empresa $\mathrm{C}$ e $\mathrm{H}$ consideram que o estado português não valoriza nem as empresa nem os deficientes e que as ajudas disponibilizadas não são equivalentes ao grau de deficiência que o indivíduo tem. Na realidade nenhuma empresa considerou as regalias sociais ou fiscais ou o apoio do estado como um dos principais motivos que levam a empresa a manter o emprego de pessoas com deficiência.

As conclusões de Seyfried (1992) sobre a importância de preparar bem estes indivíduos, e que os estágios e os períodos de experimentação do trabalho seriam fundamentais, levam a verificar que, neste momento, em 8 empresas, apenas duas dão estágios a pessoas com deficiencia.

Á excepção de algumas adaptações arquitetónicas da empresa (D, no redesenhar e readaptar o posto de trabalho, nenhuma das empresas precisou fazer modificações arquitetónicas para os funcionários que têm atualmente. Isto verifica-se também porque são poucos os casos de deficiência que necessitem deste tipo de adaptações. Já em termos organizacionais, as empresas vêm a admitir ser necessário uma maior atenção, e o destacar de um ou mais funcionários que acompanhem e ajudem o deficiente a saber fazer bem o seu trabalho.

Não foi necessário ás empresas um grande esforço em promover a aceitação e o companheirismo entre as pessoas com deficiências e os restantes colegas de trabalho, apenas sensibilizar um pouco no sentido de respeitar a pessoa com deficiência como um trabalhador igual a qualquer outro, pelo que os funcionários já compreendem que têm de ter outro cuidado na forma de agir, e adaptaram-se bem. Em muitos casos o funcionário já nem sequer é olhado como uma pessoa com deficiência, mas sim como um trabalhador como os outros.

Quanto aos aspetos decisivos que levam ao sucesso na integração profissional de pessoas com deficiência quase todas as empresa concordaram na importância da motivação do funcionário, bem como da qualificação. De salientar a referencia feita à importância de uma estimulação de base (familiar ou escolar) que lhes permita saber aprender, facto que se encontra fortemente desenvolvido nas referências teóricas realizadas na primeira parte deste trabalho.

O apoio da família foi considerado de extrema importância por parte das empresas. Considerou-se 
mesmo que o apoio familiar faz toda a diferença e que isso se verifica, nos casos analisados

O salário justo foi também apontado como um dos aspetos decisivos que levam ao sucesso na integração profissional por grande parte das empresas que participaram neste estudo, o que vem reforçar a importância da igualdade de oportunidades e do direito a um tratamento justo por parte das entidades empregadoras tal como está amplamente referido na literatura especializada.

As boas condições de trabalho e o bom ambiente de trabalho foi um aspeto também salientado por grande parte das empresas, assim como uma boa seleção do posto de trabalho, no sentido de analisar as competências e verificar onde a pessoa com deficiência melhor se enquadra.

Apenas uma empresa abordou a importância da oportunidade de crescimento profissional. Já o sentimento de utilidade e noção da importância da função que desempenha foi um aspeto salientado por metade das empresas.

Numa análise às principais barreiras que impedem a inserção profissional das pessoas com deficiência, e tendo em conta que as pessoas com deficiência devem ter a oportunidade de ganhar a vida através de um trabalho livremente escolhido, a ONU salienta que a taxa de desemprego das pessoas com deficiência tende a ser duas a três vezes superior à da restante população. Neste ámbito, algumas das empresas, consideram que quando nós queremos não há barreiras e que haverá sempre a atividade certa e que melhor se adapta à deficiência de cada funcionário. A discriminação, segundo algumas empresas, a que estas pessoas são sujeitas pela sociedade é a maior e principal barreira sendo frequente os empresários terem medo de se comprometer em contratos que depois não possam ou não queiram cumprir por falta de produtividade da pessoa com deficiência.

Quanto aos principais motivos que levam a empresa a manter o emprego de pessoas com deficiência, os mais apontados passam pelo espirito de missão, sentido de solidariedade, boa imagem pública da empresa ou o contrário.

Segundo Monteiro (2009) contratar pessoas com deficiências introduz alguma inovação, diversidade e até qualidade no trabalho. No entanto algumas empresas, consideram que por vezes a boa imagem pública da empresa até fica prejudicada, pois há sempre quem não queira ser atendido por uma pessoa com deficiência e ponha em causa a sua eficácia. Neste campo a conquista é feita pelo próprio deficiente, face a uma sociedade discriminadora. Segundo Neto \& Monteiro, 1996, atualmente, as pessoas aparentam maior tolerância e flexibilidade ao nível dos valores, não sendo "politicamente correto" expressar atitudes de rejeição mas, ao nível latente, tais atitudes perduram e a discriminação permanece.

No entender de Carvalho-Freitas \& Marques (2009) quanto maior o tempo de trabalho com pessoas com deficiência melhor é a perceção em relação ao seu desempenho, melhorando assim as suas possibilidades de inserção no mercado de trabalho. Este fato verificou-se em todas as empresas, à excepção de uma das empresas. Numa empresa foram criados laços de tal modo fortes que o funcionário se torna imprescindível. Se ele faltar durante um ou dois meses faz muita falta em termos de trabalho e em termos afetivos. Resposta semelhante teve uma outra empresa, pois não olham para o funcionário como sendo um deficiente - "ele faz tudo como uma pessoa sem deficiência”.

\section{Considerações finais}

De uma forma geral e face aos resultados apresentados neste estudo permitem-nos confirmar a importância da oportunidade de emprego dada à pessoa com deficiência, no âmbito da sua realização pessoal, profissional e da sua integração na Sociedade. Sente-se no entanto alguma falta de apoio que permita um maior acompanhamento, nomeadamente no que concerne ao estado. Este falta de apoio è financeira mas também a nível técnico no acompanhamento, planeamento e inserção destas pessoas nas empresas. É a sensibilidade por parte dos empresários e sobretudo o sentido de solidariedade que permitem ultrapassar as dificuldades sentidas. E se numa média ou grande empresa é possível estruturar esta adaptação e evolui-la em diversos sentidos, nas pequenas e micro empresas conta muito mais a afetividade que liga o empresário a estes indivíduos e que os faz descobrir, na vivência diária, os passos a dar.

Concluí-se que é fundamental a boa seleção do posto de trabalho, por forma a que a deficiência não se torne um transtorno na produtividade e qualidade do trabalho efetuado.

A questão da discriminação por parte da sociedade é ainda bastante sentida e chega a pôr em causa a boa imagem da empresa que emprega pessoas com deficiencia, como foi referido. Por outro lado concluí-se também que a colaboração por parte dos restantes colegas de trabalho na inserção da pessoa com deficiência é muito positiva, permitindo mesmo que outros valores morais e humanos venham colmatar as dificuldades sentidas. A sensibilidade desenvolvida permite então que se forme como que um núcleo protetor da pessoa com deficiência em relação à sociedade envolvente. Outro aspeto observado é que salvo poucas excepções, os casos de inclusão da pessoa com deficiência nas empresas resultam em situações bem sucedidas, e permitem perceber que não há motivos para que elas não possam competir de igual modo por um posto de trabalho tal como as pessoas ditas "normais".

Em estudos futuros será recomendável uma análise mais aprofundada e detalhada de cada questão, dado que as respostas nos levam muitas vezes a colocar outras suposições, as quais não estavam contempladas neste estudo. Aconselha-se também a recolha da visão das pessoas portadoras de deficiência, no sentido de estabelecer um paralelo com a visão dos empregadores.

\section{Referências}

Afonso, Carlos M. P. 2005. Inclusão e mercado de trabalho papel da escola na transição para a vida adulta de alunos com NEE. In , Saber (e) educar, ESE de Paula Frassinetti, 10, 53 - 66. 
Bota, L. M. C. P. da C. (2013). A Transição para a Vida Pós Escolar de Alunos com Necessidades Educativas Especiais nas Escolas Básicas dos $2^{\circ} e$ $3^{\circ}$ Ciclos e Ensino Secundário no Concelho de Faro. Universidade Fernando Pessoa. http://hdl.handle.net/10284/4198

Carvalho-Freitas, M., \& Marques, A. (2009). Pessoas com Deficiência e Trabalho: Percepção de Gerentes e Pós-Graduandos em Administração. Psicologia Ciência E Profissão, 29 (2), 244257. http://dx.doi.org/10.1590/S1414-989320090 00200004

Monteiro, C. M. dos S. (2009). Competências na Diferença - Uma Reflexão sobre a Empregabilidade do Trabalhador com Deficiência no Distrito de Aveiro. https://repositorio.uac.pt/.

Neto, M., \& Monteiro, I. (1996). Ser uma pessoa com deficiência, ser socialmente discriminada, um estudo empírico.

$1-$

18. https://sapientia.ualg.pt/bitstream/10400.1/1 922/1/CIDERdef.

Seyfried, E. (1992). Condições do sucesso da inserção dos deficientes na vida profissional. Accessed in March 30, 2014. Retrieved from http://bookshop.europa.eu/pt/condi-es-do-sucessoda-inser-o-dos-deficientes-na-vida-profissional-pb HX7592227/
Silva, A., Alves, J., Ribas, F., \& dos Santos, C. (2010). Homem um ser Social? Os desafios na Inserção de Portadores de Deficiência no Mercado de Trabalho. XIII Semaad - Seminários Em Administração. Accessed in March 30, 2014. Retrieved from http://www.ead.fea.usp.br/semead/13semead/resul tado/trabalhosPDF/868.pdf

UNESCO e Ministério da Educação e Ciência de Espanha. (1994). Declaração de Salamanca Conferência Mundial sobre Necessidades Educativas Especiais: Acesso e Qualidade. Accessed in March 30, 2014. Retrieved from http://redeinclusao.web.ua.pt/files/fl_9.pdf

Von Groote, P. M., Bickenbach, J. E., \& Gutenbrunner, C. (2011). The World Report on Disability implications, perspectives and opportunities for physical and rehabilitation medicine (PRM). Journal of Rehabilitation Medicine, 43(10), 86975. doi:10.2340/16501977-0872 